\title{
Ciclos Reais Brasileiros em Dois Setores
}

Fabio Kanczuk

Professor da FEA-USP - Departamento de Economia

\section{RESUMO}

Construímos um modelo de equilíbrio geral dinâmico de dois setores com o intuito de investigar o comportamento dos ciclos reais brasileiros. Quando os investimentos dos dois setores são agregados de acordo com uma Cobb-Douglas para formação de capital, o modelo é consistente com as volatilidades cíclicas dos componentes das contas nacionais e com a natureza contracíclica das exportações líquidas e do câmbio real. Caso a elasticidade de substituição entre o consumo de comercializáveis e de não comercializáveis seja baixa, o modelo também reproduz a volatilidade observada no câmbio real.

\section{PALAVRAS-CHAVE}

oscilações, câmbio real, balança comercial

We construct a two-sector dynamic general equilibrium model to investigate the behavior of the Brazilian business cycles. When investments from each sector are aggregated according to a Cobb-Douglas for capital formation, the model is consistent with the cyclical volatilities of national income components as well as with the countercyclical character of net exports and real exchange rates. If the elasticity of substitution between consumptions of tradeables and non-tradeables is low, the model can also reproduce the observed real exchange rates volatilities.

KEY WORDS oscillations, real exchange rate, trade balance

JEL Classification

E32, F32 


\section{INTRODUÇÃO}

Vários artigos recentes (KANCZUK \& FARIA, 2000; KANCZUK, 2002) mostraram que, ao contrário do que muitos pesquisadores acreditavam, os comportamentos de alta freqüência de várias séries macroeconômicas brasileiras podem ser reproduzidos por modelos de Equilíbrio Geral Dinâmico. Uma próxima etapa natural dessa linha de pesquisa é verificar se este sucesso também se aplica caso os modelos sejam mais detalhados e os dados mais desagregados. Nesse contexto, o presente trabalho propõe um modelo com dois setores, um de bens comercializáveis e outro de bens domésticos (não-comercializáveis), e investiga se alguns fatos estilizados da economia brasileira podem ser racionalizados por meio de modelos de ciclos reais.

Há várias razões para o nosso interesse por modelos de dois setores que possam satisfatoriamente mimetizar nossa economia. A mais óbvia é poder realizar experimentos em que os diferentes choques econômicos sejam mais precisamente identificados. Por exemplo, seria interessante investigar as diferenças entre os impactos de um choque de petróleo, que atinge diretamente o setor comercializável, e aqueles provenientes de um choque institucional, que atinge uniformemente todos os setores econômicos. De forma mais geral, muitas das questões relacionadas ao comércio exterior não podem ser satisfatoriamente respondidas com modelos de um só setor. A própria determinação do câmbio real só é possível se o modelo tiver dois setores.

Nosso modelo é semelhante aos de Stockman e Tesar (1995) e de Pessôa (1999), que também estudam modelos de dois setores aplicados, respectivamente, aos Estados Unidos e ao Brasil. Mas, diferentemente desses artigos, temos a particular preocupação em especificar a interligação entre os investimentos provenientes dos dois setores para a formação de dois tipos de capital, de tal forma que o modelo possa reproduzir adequadamente o comportamento dessas séries de investimento.

Devido às limitações computacionais, estudamos somente duas formas de agregação das séries de investimento. Uma delas utiliza uma função Leontieff e a outra uma Cobb-Douglas. Os resultados obtidos mostram que, nesse segundo caso, o modelo reproduz os principais fatos estilizados das flutua- 
ções brasileiras, incluindo o comportamento contracíclico das exportações líquidas e do câmbio real.

Um tópico que tem recebido bastante atenção em Finanças Internacionais é a necessidade de rigidez de preços para explicar o comportamento do câmbio real. (OBSTFELD \& ROGOFF, 1995). De fato, quando o parâmetro de substituição entre as duas formas de consumo é calibrado de acordo com Ostry e Reinhart (1992), nossas economias apresentam volatilidades do câmbio real quase dez vezes menor do que a observada nos dados. É bem provável que essa discrepância seja conseqüência, ao menos em parte, da nossa hipótese de completa flexibilidade dos preços. Contudo, como a calibração desse parâmetro está longe de ser consenso entre os economistas, em razão da pouca robustez do único estudo conhecido sobre o assunto, colocamos à prova nossas economias artificiais com valores alternativos. De acordo com os resultados obtidos, apesar do modelo não incorporar rigidez de preços, a volatilidade do câmbio real também pode ser reproduzida caso a elasticidade de substituição entre as duas formas de consumo seja suficientemente baixa.

A seção a seguir explicita os modelos utilizados. Na seção 2 descrevem-se os dados e a calibração. Na seção 3 são apresentados os fatos estilizados para os ciclos reais brasileiros e estes são comparados com as nossas simulações. A última seção conclui o trabalho.

\section{MODELO}

Nossa economia artificial é povoada por um continumm de famílias idênticas e de vida infinita, com nomes no intervalo $[0,1]$. Cada uma dessas famílias tem uma dotação de tempo para cada período, que deve ser repartida entre lazer $\left(l_{t}\right)$, trabalho no setor de comercializáveis $\left(h_{T t}\right)$ e trabalho no setor de domésticos $\left(h_{N}\right)$. A dotação de tempo é normalizada para uma unidade, isto é, $h_{t}+l_{t}=1$, em que $h_{t}=h_{T t}+h_{N t}$. Adicionalmente, as famílias possuem um nível inicial de capital para produção de bens comercializáveis $k_{T o}$ e de capital para produção de bens domésticos $k_{N_{o}}$ que elas alugam para as 
firmas, e que podem aumentar por meio investimentos, e um nível inicial de títulos $b_{o}$, que rendem uma taxa de juros estocástica $r_{t}$.

A utilidade das famílias para cada período é definida em termos das seqüências estocásticas de consumo e lazer:

$$
U_{s}=E_{s} \sum_{t=s}^{\infty}[(1+\eta) \beta]^{t-s} u\left(c_{t}^{\prime}, h_{t}^{\prime}\right)
$$

em que $c_{t}^{\prime}$ e $b^{\prime}{ }_{t}$ representam sequiências Arrow-Debreu de "consumo composto" e trabalho contingentes ao estado em termos per capita, $\eta$ representa a taxa de crescimento da população, e $\beta \in[0,1]$ um parâmetro de desconto. Por "consumo composto", $(c)$, compreende-se uma agregação (com elasticidade de substituição constante) de consumo de bens comercializáveis $\left(c_{T}\right)$ e de bens domésticos $\left(c_{N}\right)$,

$$
c=\left(\omega c_{T}^{\rho}+(1-\omega) c_{N}^{\rho}\right)^{1 / \rho}
$$

Utilizamos a forma funcional para a utilidade instantânea proposta por Greenwood, Hercowitz e Huffman (1988), cuja propriedade é de que a elasticidade intertemporal de substituição associada com o lazer é zero:

$$
u(c, 1-h)=\left(c-a h^{v}\right)^{1-\sigma} /(1-\sigma)
$$

Para que economias com essas preferências sejam consistentes com um estado estacionário em que há crescimento, é necessário que a desutilidade de trabalhar no mercado aumente com o nível de progresso tecnológico. Este efeito pode ser interpretado como progresso tecnológico associado com a produção em atividades domésticas (veja nota de rodapé 11 em CHRISTIANO, EICHENBAUM \& EVANS, 1997). A utilização dessa forma funcional para as preferências é essencial para a obtenção de um caráter contracíclico para exportações líquidas, conforme mostrado nos trabalhos de Correia Neves e Rebelo (1995) e Kanczuk (2001).

As famílias que povoam a economia ofertam trabalho e capital às firmas que têm acesso a tecnologias descritas por função de produção Cobb-Douglas:

$$
Y_{T t}^{\prime}=F\left(z_{T t}, K_{T t}^{\prime}, H_{T t}^{\prime}\right)=A_{T} \exp \left(z_{T t}\right)(1+\gamma)^{(1-\theta T) t} K_{T t}^{\prime \theta T}\left((1+\eta)^{t} H_{T t}^{\prime}\right)^{1-\theta T}
$$


$Y_{N t}^{\prime}=F\left(z_{T t}, K^{\prime}{ }_{N t}, H^{\prime}{ }_{N t}\right)=\exp \left[\left(\sigma_{N} / \sigma_{T}\right) z_{T t}\right](1+\gamma)^{(1-\theta N) t} K_{N t}^{\prime^{\theta N}}\left((1+\eta)^{t} H^{\prime}{ }_{N t}\right)^{1-\theta N}$

em que trabalho $\left(H_{T \mathrm{t}}^{\prime}\right.$ e $\left.H^{\prime}{ }_{N t}\right)$ e capital acumulado $\left(K_{T t}{ }_{T}\right.$ e $\left.K_{N t}\right)$ são insumos, $\gamma$ representa a taxa de crescimento tecnológico, e $z_{N t}$ é um parâmetro estocástico de produtividade.

O estado estacionário dessa economia é um crescimento balanceado ( $b a-$ lanced growth path). Para trabalharmos com variáveis sem tendência, normalizamos a equação anterior pelo fator de crescimento da economia $(1+$ $\eta)(I+\gamma)$, e denotamos $K_{t}=K_{t}^{\prime} /[(I+\eta)(I+\gamma)]^{t}$, com expressões análogas para as outras variáveis. De forma semelhante, para variáveis que já estão em termos per capita utilizamos $c_{t}=c_{t}^{\prime} /(1+\gamma)^{t}$.

Assumimos que $z_{t}$ e $r_{t}$ evoluem de acordo com as leis de formação:

$$
\begin{aligned}
& z_{T t+1}=\rho_{z} z_{T t}+\varepsilon_{z T t} \\
& r_{t+1}=\left(1-\rho_{r}\right) r^{m}+\rho_{r} r_{t}+\rho_{y} y_{t}+\varepsilon_{r t}
\end{aligned}
$$

em que $\varepsilon_{z T}$ e $\varepsilon_{r}$ são distribuídas de acordo com uma normal, com média zero e desvios padrões $\sigma_{T}$ e $\sigma_{r}$. A lei de formação para o resíduo de Solow, $z_{T t}$, é usual na literatura. Note que o setor doméstico está sujeito aos mesmos choques tecnológicos que o setor comercializável, mas que os desvios padrões dos choques nos dois setores são diferentes: respectivamente $\sigma_{N}$ e $\sigma_{T}$. Para a taxa de juros real, $r_{t}$, estamos assumindo que a política monetária tem a forma proposta por Taylor (1999). Como nosso modelo não contempla inflação (ou outras variáveis nominais), a taxa de juros é somente uma função das taxas de juros anteriores e do hiato do produto $\left(y_{t}\right)$. O hiato do produto, como usual, é o produto filtrado pelo filtro de Hodrick-Prescott.

O capital deprecia-se exponencialmente a uma taxa $\delta$ e os consumidores adicionam ao estoque de capital por meio de investimentos de uma parte do produto a cada período. Investimentos em $t$ produzem capital em $t+1$, de forma que as leis de formação para capital agregado são:

$$
(1+\eta)(1+\gamma) K_{T t+1}=(1-\delta) K_{T t}+I_{T t}
$$




$$
(1+\eta)(1+\gamma) K_{T t+1}=(1-\delta) K_{T t}+I_{T t}
$$

$I_{T}$ e $I_{N}$ são, por sua vez, funções de investimentos provenientes dos dois setores, comercializáveis (máquinas e equipamentos) e domésticos (sobretudo insumos da construção civil). Neste trabalho assumimos que a agregação dos dois investimentos é feita de duas formas. Inicialmente, supomos que a agregação é feita via coeficientes fixos (Leontieff), ou seja,

$$
\begin{aligned}
& I_{T}=\operatorname{Min}\left\{I_{T T} / \alpha, I_{N T} /(1-\alpha)\right\} \\
& I_{N}=\operatorname{Min}\left\{I_{T N} / \alpha, I_{N N} /(1-\alpha)\right\}
\end{aligned}
$$

Em seguida supomos que a agregação é feita de acordo com uma função Cobb-Douglas, ou seja,

$$
\begin{gathered}
I_{T}=I_{T T}^{\alpha} I_{N T}^{1-\alpha} \\
I_{N}=I_{T N}^{\alpha} I_{N N}^{1-\alpha}
\end{gathered}
$$

Vale notar que a presença de um só subscrito indica o investimento após a agregação, e quando há dois subscritos, o primeiro indica de que setor o investimento é proveniente, e o segundo qual o seu destino.

Em princípio seria possível estudar formas de agregação mais gerais que estas duas, ou pelo menos uma forma "CES", com elasticidade de substituição constante. Esta tarefa não é aqui contemplada por causa de limitações computacionais. Em razão do elevado número de variáveis de estado na resolução do problema de programação dinâmica, recorreremos à usual metodologia de aproximar o problema a um linear-quadrático, via uma “expansão de Taylor” em torno do estado estacionário. Contudo, uma vez que o problema será transformado em um linear-quadrático, deixa de ser possível capturar as diferentes formas de agregação.

1 Na prática, estamos limitados computacionalmente a resolver um caso Leontieff ou um caso linear. Conforme discutiremos a seguir, nossas soluções denominadas Cobb-Douglas correspondem a uma aproximação linear, cujos coeficientes são obtidos por meio de uma expansão de Taylor realizada sobre uma função Cobb-Douglas. 
As firmas alugam capital e contratam trabalho. Em contraste com os modelos mais usuais de ciclos reais, assumimos que as firmas também têm que permanecer, em cada período, com uma fração $\chi$ da produção, na forma de capital de giro. Esta restrição ocorre devido à falta de sincronismo entre as receitas e despesas, e faz com que as firmas permaneçam com os recursos necessários para pagar parte dos salários e do aluguel do capital em caixa. Note que essa restrição é análoga a uma de cash-in-advance, mas ocorre no lado da produção.

Denotamos por $M_{t}$ a quantidade de capital de giro entre $t$ e $(t+1)$. Esses recursos são emprestados pelo governo, e devolvidos no período seguinte. Alternativamente, pode-se pensar que as firmas tomam esses empréstimos de intermediários financeiros, mas, como no nosso modelo o governo transfere recursos de volta às famílias, e seria exatamente isso que intermediários financeiros fariam com seus lucros, esta hipótese é inofensiva. Podemos escrever o problema da firma (onde, por simplicidade, excluímos os subíndices relativos a comercializáveis e domésticos) como:

$$
\operatorname{Max}\left\{\sum_{t=s}^{\infty} \frac{\left[Y_{t}-w_{t} H_{t}-u_{t} K_{t}-M_{t}+M_{t-1}\right]}{\prod_{j=s}^{t}\left(1+r_{j}\right)^{j-s}}\right\}
$$

em que $w$ e $u$ correspondem aos produtos marginais do trabalho e do capital, sujeito às restrições de capital de giro,

$$
M_{t} \geq \chi Y
$$

Note que como o capital de giro não rende juros, essa desigualdade sempre será restritiva (binding), e que para $\chi=0$ o problema da firma se reduz ao caso usual. $\mathrm{O}$ problema das firmas transformado pela restrição de capital de giro é, em princípio, complicado. Contudo, ele pode ser dividido em problemas de maximização para cada período (vide KANCZUK, 2002). As famílias, em contraste, resolvem um problema intertemporal, e têm que formar expectativas sobre preços futuros. Elas escolhem consumo, investimento, demanda por (novos) títulos externos e horas de trabalho em cada 
data para maximizar o valor descontado da utilidade sujeito a seqüências de restrições orçamentárias e leis de formação de capital e títulos:

$$
\begin{gathered}
c_{N t}+e_{t} c_{T t}+\left(i_{N T t}+e_{t} i_{T T}\right)\left[1+\phi\left(i_{T t} / k_{T t}\right)\right]+\left(i_{N N t}+e_{t} i_{T N}\right)\left[1+\phi\left(i_{N t} / k_{N t}\right)\right]+ \\
\mid+e_{t} n x_{t} \leq u_{N t} k_{N t}+w_{N t} k_{N t}+e_{t}\left(u_{T t} k_{T t}+w_{T t} k_{T t}\right) \\
(1+\eta)(1+\gamma) k_{T t+1}=(1-\delta) k_{T t}+i_{T t} \\
(1+\eta)(1+\gamma) k_{N t+1}=(1-\delta) k_{N t}+i_{N t} \\
(1+\eta)(1+\gamma) b_{t+1}=\left(1+r_{t}(1-\tau)\right) b_{t}+n x_{t}
\end{gathered}
$$

As seqüências $e_{t}$ e $n x_{t}$ representam, respectivamente, o câmbio real e as exportações líquidas. A função $\phi\left(i_{t} / k_{t}\right)$ é convexa, e representa os custos associados à instalação de capital, uma prática comum em modelos de economia pequena e aberta. Assumimos que sua forma funcional é $\phi\left(i_{t} / k_{t}\right)$ $=\phi\left(i_{t} / k_{t}-\delta-\eta-\gamma-\eta \gamma\right)^{2}$, em que, com leve abuso de notação, o $\phi$ do lado direito da equação é uma constante. Esta formulação implica que os custos sejam zero no estado estacionário.

Seria natural esperar que o problema das famílias envolvesse a compra de títulos do governo (domésticos) assim como de títulos externos, e que o governo mantivesse posições tanto em títulos domésticos como em títulos externos. No entanto, é preciso notar que especificamos o problema das famílias com respeito somente à posição de títulos externos. Fazendo isto, estamos assumindo que os títulos externos e domésticos são substitutos perfeitos e adicionando ao problema do setor privado a restrição orçamentária do setor público. Assim, as posições dos agentes referem-se à posição do País como um todo com relação ao resto do mundo, incluindo tanto a dívida externa do setor privado como a dívida externa do setor público. Além disso, a dívida doméstica do governo e os ativos domésticos do setor privado desaparecem, já que estes se cancelam. Ao resolver o problema dessa forma, adicionando a restrição orçamentária do governo à do setor privado, estamos assumindo que o setor público é solvente, no sentido Ponzi. Vale notar também que o consumo do governo não entra nas preferências das famílias. Esta hipótese pode ser entendida como separabilidade entre os bens públicos e privados na função de utilidade. 
Utilizamos aqui o conceito de Equilíbrio Competitivo Recursivo. As variáveis de estado para cada família são $\left(z_{t}, r_{t}, K_{t}, k_{t}, B_{t}, b_{t}\right)$. A equação de otimalidade no problema das famílias pode ser escrita da seguinte forma:

$$
\begin{aligned}
& V\left(z_{T}, r, K_{T}, k_{T}, K_{N}, k_{N}, B, b\right)=\operatorname{Max}\{u(c, 1-h)+\beta(1+\eta) \\
& \left.E\left[V\left(z_{T}{ }^{\prime}, r^{\prime}, K_{T}{ }^{\prime}, k_{T}{ }^{\prime}, K_{N}{ }^{\prime}, k_{N}{ }^{\prime}, B^{\prime}, b^{\prime}\right)\right]\right\}
\end{aligned}
$$

tal que

$$
\begin{aligned}
& c_{N}+e c_{T}+\left(i_{N T}+e i_{T T}\right)\left[1+\phi\left(i_{T} / k_{T}\right)\right]+\left(i_{N N}+e i_{T N}\right)\left[1+\phi\left(i_{N} / k_{N}\right)\right]+e n x \leq \\
& \leq u_{N} k_{N}+w_{N} k_{N}+e\left(u_{T} k_{T}+w_{T} k_{T}\right) \\
& (1+\eta)(1+\gamma) k_{T}^{\prime}=(1-\delta) k_{T}+i_{T} \\
& (1+\eta)(1+\gamma) k_{N}^{\prime}=(1-\delta) k_{N}+i_{N} \\
& (1+\eta)(1+\gamma) b^{\prime}=(1+r(1-\tau)) b+n x \\
& (1+\eta)(1+\gamma) k_{T}^{\prime}=(1-\delta) k_{T}+I_{T} \\
& (1+\eta)(1+\gamma) k_{N}^{\prime}=(1-\delta) k_{N}+I_{N} \\
& (1+\eta)(1+\gamma) B^{\prime}=(1+r(1-\tau)) B+N X \\
& z_{T}^{\prime}=\rho_{z} z_{T}+\varepsilon_{z}
\end{aligned}
$$

Um equilíbrio competitivo recursivo para essa economia consiste de uma função valor $V\left(z_{T}, r, K_{T}, k_{T}, K_{N}, k_{N}, B, b\right)$; um conjunto de regras de política para as famílias, $c_{T}\left(z_{T}, r, K_{T}, k_{T}, K_{N}, k_{N}, B, b\right), c_{N}\left(z_{T}, r, K_{T}, k_{T}, K_{N}, k_{N}, B, b\right), i_{T T}\left(z_{p}\right.$, , $\left.K_{T}, k_{T}, K_{N}, k_{N}, B, b\right), i_{T N}\left(z_{p}, r K_{T}, k_{T}, K_{N}, k_{N}, B, b\right), i_{N T}\left(z_{p}, r, K_{T}, k_{T}, K_{N}, k_{N}\right.$, $B, b), i_{N N}\left(z_{p}, r K_{T}, k_{T}, K_{N}, k_{N}, B, b\right), n x\left(z_{p} r, K_{T}, k_{T}, K_{N}, k_{N}, B, b\right), h_{T}\left(z_{p}, r K_{T}\right.$, $\left.k_{T}, K_{N}, k_{N}, B, b\right), \mathrm{e}_{N}\left(z_{p}, K_{T}, k_{T}, K_{N}, k_{N}, B, b\right)$; um conjunto correspondente de regras de política agregada per capita, $C_{T}\left(z_{p}, r, K_{T}, K_{N}, B\right), C_{N}\left(z_{p}, r, K_{T}, K_{N}\right.$ , B), $I_{T T}\left(z_{p}, r, K_{T}, K_{N}, B\right), I_{T N}\left(z_{p}, r K_{T}, K_{N}, B\right), I_{N T}\left(z_{p}, r K_{T}, K_{N}, B\right), I_{N N}\left(z_{p}\right.$, , $\left.K_{T}, K_{N}, B\right), N X\left(z_{p}, r K_{T}, K_{N}, B\right), H_{T}\left(z_{p}, r K_{T}, K_{N}, B\right)$ e $H_{N}\left(z_{p}, r K_{T}, K_{N}, B\right)$, e funções dos preços dos fatores, $w_{T}\left(z_{p}, r, K_{T}, K_{N}, B\right), w_{N}\left(z_{p} r, K_{T}, K_{N}, B\right), u_{T}\left(z_{p}\right.$ r, $\left.K_{T}, K_{N}, B\right)$, e $u_{N}\left(z_{p}, r, K_{T}, K_{N}, B\right)$, tal que essas funções satisfaçam:

i) o problema das famílias

ii) o problema das firmas

iii) a política do governo, isto é, $r^{\prime}(z, r, K, B)=\left(1-\rho_{\nu}\right) r^{m}+\rho_{r} r+\rho_{y} y(z, r$, $\left.K_{T}, K_{N}, B\right)+\varepsilon_{r}$. 
iv) as condições de equilíbrio de mercado (market clearing), isto é, $c_{T}\left(z_{T}\right.$ r, $\left.K_{T}, K_{T}, K_{N}, K_{N}, B, b\right)=C_{T}\left(z_{p}, r, K_{T}, K_{N}, B\right)$, com expressões análogas para as demais funções individuais e agregadas per capita, e o equilíbrio em cada um dos setores, isto é:

$$
\begin{aligned}
& C_{T}+I_{T T}\left[1+\phi\left(I_{T} / K_{T}\right)\right]+I_{T N}\left[1+\phi\left(I_{N} / K_{N}\right)\right]+N X=u_{T} K_{T}+w_{T} H_{T^{\prime}} \mathrm{e} \\
& C_{N}+I_{N T}\left[+\phi\left(I_{T} / K_{T}\right)\right]+I_{N N}\left[1+\phi\left(I_{N} / K_{N}\right)\right]=u_{N} K_{N}+w_{N} H_{N}
\end{aligned}
$$

\section{DADOS E CALIBRAÇÃO}

Em virtude da reduzida disponibilidade de dados desagregados, a análise ficou restrita ao período 1991 a 2001. Lançamos mão dos dados trimestrais obtidos por meio do IPEADATA (www.ipea.gov.br). Para as ponderações necessárias, utilizamos sempre como referência os valores relativos ao ano 1996.

Produto é o índice real do PIB a preços de mercado, base móvel (para o deflator). O setor comercializável corresponde à soma da Agropecuária à Indústria, com exceção dos subsetores Construção Civil e SIUP. O setor doméstico corresponde ao restante do PIB. Como é usual, tais séries foram dessazonalizadas, via fatores multiplicativos.

O investimento total corresponde à fração relativa ao investimento, multiplicada pelo PIB. A parte do investimento que é proveniente do setor doméstico corresponde à série de Insumos da Construção Civil. O restante é o investimento proveniente do setor comercializável (máquinas e equipamentos, excluídas as exportações líquidas destes).

Como não dispomos de uma boa série de consumo do governo trimestral, analisamos o comportamento da série correspondente à soma do consumo privado com o consumo do governo. As séries de consumo de comecializáveis e consumo de domésticos são obtidas simplesmente pela subtração dos investimentos das séries de produto. A rigor, a série de exportações líquidas também deveria ser descontada, mas como para o Brasil elas re- 
presentam uma fração bem pequena do PIB (menos de 2\%), elas podem ser desconsideradas, com a vantagem de não poluírem a série de consumo. Como não está disponível uma série de bens duráveis, eles estão incluídos na série de consumo ao invés de serem adicionados ao investimento, como sugere a literatura de ciclos reais. Vale ressaltar também não se dispõe de uma série de horas trabalhadas. No entanto, trabalhos anteriores sugerem que os modelos reproduzem razoavelmente os indicadores fornecidos pela PME (emprego nas regiões metropolitanas).

A taxa de juros real é a SELIC descontada pelo IPCA centrado. Aqui está sendo usada a hipótese de substituição perfeita entre títulos domésticos e internacionais, que é justificada pela arbitragem entre os títulos que ocorre no mercado secundário. Além disso, há evidência anedótica de que a SELIC é a taxa com efeitos mais importantes sobre a economia, e a "IS dinâmica" é uma das únicas relações estimadas com alguma robustez para o Brasil, um fato estilizado que queremos que seja reproduzido por nossa economia artificial.

Utilizando as médias no período, calibramos $r^{m}=5,1 \%, \eta=0,36 \%$, e $\gamma=$ 0,19\%. Dividindo a lei de formação do passivo externo pelo PIB obtemos,

$$
(1+\eta)(1+\gamma) B_{t+1} / Y_{t+1}=\left(1+r_{t}(1-\tau)\right) B_{t} / Y_{t}+N X_{t} / Y_{t}
$$

O valor médio das exportações líquidas no período foi de - $0,43 \%$ do PIB. O valor médio do passivo externo líquido foi de $43 \%$ do PIB (anual), mas houve um crescimento deste valor de $2,3 \%$ ao ano. Para incorporar esse crescimento (que significa um desvio de estado estacionário), sem abandonar a simplicidade do modelo, incluímos o crescimento do passivo externo no lado esquerdo da equação. Com isso, os valores dos parâmetros calibrados correspondem a uma situação em que não haveria desvio do estado estacionário. Empregando esses valores na equação acima obtivemos $\tau=84 \%$. Note que $\tau$ não significa necessariamente impostos sobre os títulos internacionais, mas qualquer diferença de remuneração entre o rendimento da SELIC e 
do passivo externo. Da equação de Euler para os títulos governamentais obtivemos $\beta=0,99$.

Para as frações correspondentes à remuneração do capital utilizamos $\theta_{T}=$ 0,57 , e $\theta_{N}=0,31$. Obtivemos esses valores mantendo a razão entre eles que consta das Contas Nacionais (0,71/039), reduzindo, todavia, suas magnitudes (via simples regra de três) segundo a proporção entre o observado nas Contas Nacionais para o PIB total $(0,49)$ e valores previamente calibrados também para o PIB total (0,39, segundo KANCZUK, 2002). Esta metodologia se justifica pelo fato de o IBGE superestimar esses valores nas contas nacionais, adicionando "indevidamente" parte da remuneração dos autônomos à remuneração do capital.

Da razão entre as equações de Euler para os investimentos (no estado estacionário), temos:

$$
\alpha\left(I_{N T}+I_{N N}\right)=e(1-\alpha)\left(I_{T T}+I_{T N}\right)
$$

Sem perda de generalidade, assumimos que $e=1$. Por meio da relação entre os investimentos provenientes de cada setor observada nos dados, temos $\alpha=0,29$.

Da razão entre as leis de formação de capital temos:

$$
\left(I_{N} / I_{T}\right) /\left(Y_{N} / Y_{T}\right)=\theta_{N} / \theta_{T}
$$

Utilizando a relação entre os produtos dos dois setores (29/71) e a fração do produto total que corresponde ao investimento (20\%), obtivemos a fração do investimento sobre o produto em cada um dos setores, $I_{T} / Y_{T}=$ $29 \%$ e $I_{N} / Y_{N}=16 \%$. Por meio de cada uma das leis de formação de capital obtivemos $K_{T} / Y_{T}=4,2$ e $K_{N} / Y_{N}=2,3$ (anuais), que implicam $K / Y=2,9$, em linha com outras calibrações prévias. (KANCZUK, 2002).

Utilizando as equações de Euler para os investimentos (qualquer uma delas), calibramos o valor de $\delta$. Como essas equações de Euler são diferentes para os diferentes casos de agregação, dispomos dois valores distintos para a depreciação. No caso de agregação via Leontieff, temos $\delta_{L}=4,7$ (anual), 
para o caso Cobb-Douglas, $\delta_{C D}=4,0 \%$. Embora não tenhamos estudado completamente um caso geral de agregação, nossa intuição é de que um valor exógeno de depreciação permitiria calibrar um parâmetro correspondente à elasticidade de substituição entre os dois tipos de investimento, no caso de uma função CES (elasticidade de substituição constante) genérica. Vale notar, contudo, que não dispomos de um valor exógeno preciso para a depreciação brasileira, e que em ambos os casos os valores aqui obtidos são próximos de calibrações anteriores.

Seguindo Ostry e Reinhart (1992), utilizamos $\rho=-0,32$, mas verificaremos a robustez desse parâmetro a seguir. Dado um valor para $\rho$ por meio da razão das equações de Euler para o consumo de comercializáveis e domésticos, e da razão observada nos dados entre esses dois consumos (29/71), obtemos $\omega$. Para $\rho=-0,32$, o valor é $\omega=0,24$.

Seguindo Greenwood, Hercowitz e Huffman (1988), utilizamos $\sigma=2$. Em contrapartida, empregamos $v_{2}=1,1$, enquanto esses autores utilizam $v_{2}=1,6$, mas reportam que as estimações disponíveis para a elasticidade intertemporal do trabalho divergem bastante. Há duas razões para nossa escolha. Do ponto de vista teórico, que parece ter se tornado claro somente após 1988 com os modelos de "household production", esse valor corresponde à desutilidade relativa de trabalhar em atividades domésticas vis-à-vis às atividades do mercado, as quais são, a princípio, equivalentes (vide novamente CHRISTIANO, EICHENBAUM \& EVANS, 1997). Do ponto de vista empírico, somente valores baixos (inferiores a 1,2) desse parâmetro são consistentes com uma Balança Comercial contracíclica. Como a forma funcional utilizada restringe $v$ a valores superiores à unidade, escolhemos $v_{2}=1,1$.

Fazendo uso da equação de Euler do trabalho (qualquer uma delas), e sabendo que a fração de horas alocadas para o trabalho é de cerca de um terço, calibramos $v_{1}=1,1$. Utilizando a razão entre as equações de Euler do trabalho (arbitragem no mercado de trabalho) obtivemos $A_{T}=0,37$. É preciso notar que o coeficiente no setor doméstico é o numerário, sem perda de generalidade. 
Para calibrar o parâmetro da restrição de capital de giro $\chi$ calculamos a diferença entre os ativos líquidos (excluindo os investimentos financeiros) e passivos líquidos (excluindo empréstimos de curto prazo) para todas as empresas listadas na BOVESPA entre os anos de 1996 e 1999. A média ponderada (pelo tamanho das empresas) dessa diferença dividida pelas vendas totais de cada empresa é bastante estável no tempo, e tem média $\chi=11 \%$.

Os parâmetros para o processo estocástico de $v_{t}$ são obtidos por meio de uma regressão ordinária de minimização de mínimos quadrados (OLS), como sugerido por Taylor (1999). Os resultados mostram que o coeficiente para o hiato do produto $\left(\rho_{y}\right)$ não é estatisticamente significativo ( $\mathrm{p}$-valor igual a $74 \%$ ), e o coeficiente para a taxa de juros defasada é relevante e igual a $\rho_{r}=$ 0.33 (p-valor igual a $0,8 \%$ ). O resíduo da regressão indica que $\sigma_{r}=5,7 \%$.

Como não há uma série de horas trabalhadas para o Brasil, não podemos seguir a estratégia de computar o resíduo de Solow e utilizá-lo para estimar o processo estocástico associado com os choques tecnológicos. Por este motivo, apelamos para a estratégia alternativa de escolher os parâmetros de forma a reproduzir a correlação serial do PIB. Seguindo a literatura para os Estados Unidos, escolhemos $\rho_{z}=0,95$.

Finalmente, os parâmetros $\sigma_{T}, \sigma_{N}$ e $\phi$ são escolhidos de forma tal que as volatilidades do PIB e do investimento das séries simuladas se aproximem às dos dados, conforme discussão a seguir.

Os parâmetros calibrados, em termos trimestrais, estão sumariados na seguinte tabela:

\begin{tabular}{cccccccccccc}
\hline$\beta$ & $\eta$ & $v_{1}$ & $v_{2}$ & $\sigma$ & $\rho$ & $\omega$ & $\gamma$ & $A_{T}$ & $\theta_{\mathrm{T}}$ & $\theta_{\mathrm{N}}$ & $\alpha$ \\
\hline 0,99 & $0,36 \%$ & 1,1 & 1,1 & 2,0 & $-0,32$ & 0,24 & $0,19 \%$ & 0,37 & 0,57 & 0,31 & 0,29 \\
\hline
\end{tabular}

\begin{tabular}{cccccccccc}
\hline$\delta_{L}$ & $\delta_{C D}$ & $\rho_{Z}$ & $\chi$ & $R^{M}$ & $B / Y$ & $\tau$ & $\rho_{R}$ & $\rho_{Y}$ & $\sigma_{R}$ \\
\hline $1,2 \%$ & $1,0 \%$ & 0,95 & 0,11 & $5,1 \%$ & $-1,7$ & $84 \%$ & 0,33 & 0 & $5,7 \%$ \\
\hline
\end{tabular}




\section{FATOS ESTILIZADOS E SIMULAÇÕES}

O passo seguinte foi computar o equilíbrio utilizando as técnicas computacionais de aproximação do problema a um linear quadrático (veja COOLEY, 1995), simulando as economias artificiais para comparar com os dados brasileiros. Uma particularidade computacional de nosso modelo, no caso da especificação Cobb-Douglas, é a imprecisão numérica devido à aproximação linear das leis de formação de capital. Isto é, como estas leis de formação estão aproximadas a suas formas lineares, não capturam o fato de os investimentos de cada setor apresentarem retornos decrescentes, tornando-se mais imprecisas conforme se afastam do estado estacionário. Apesar do mesmo ser verdade com relação à aproximação da função de utilidade a uma forma quadrática, uma restrição à forma linear (primeira ordem vis-à-vis à segunda ordem em uma aproximação de Taylor) implica maiores imprecisões. Vale notar também que um modelo com agregação linear não implicaria esse tipo de imprecisão computacional, mas seus estados estacionários corresponderiam a soluções de canto (a menos que fosse utilizada uma calibração específica, com medida zero).

Para caracterizar o comportamento cíclico das séries brasileiras, primeiramente computamos os logaritmos de todas as variáveis, com exceção da balança comercial e da taxa de juros, e depois removemos suas freqüências baixas utilizando um filtro de Hodrick-Prescott (com parâmetro 1600). Como as exportações líquidas assumem valores negativos, expressamos sua série como desvios em relação à média, utilizando a aproximação local $\log \left(n x_{t}\right): n x_{t} / \operatorname{média}\left(n x_{t}\right)-1$. Em seguida, prosseguimos com a filtragem via filtro Hodrick-Prescott.

A primeira coluna das Tabelas 1, 2 e 3 mostra as propriedades das flutuações cíclicas brasileiras. A Tabela 1 indica as volatilidades das séries e a Tabela 2 as correlações contemporâneas das diversas séries com a série do PIB. A Tabela 3 apresenta os coeficientes da chamada "IS dinâmica", uma regressão simples do hiato do produto (PIB filtrado) em sua defasagem e nos juros reais contemporâneos. 


\section{TABELA 1 - DESVIOS PADRÕES DAS SÉRIES (EM \%) FILTRADAS}

\begin{tabular}{lccc}
\hline Variável & Brasil & Leontieff & Cobb-Douglas \\
\hline PIB & 1,9 & 4,7 & 2,3 \\
PIB Comerc. & 3,1 & 3,0 & 2,9 \\
Consumo Comerc. & 3,1 & 3,9 & 2,5 \\
Invest. Comerc. & 13 & 13 & 14 \\
PIB Domést. & 1,6 & 6,4 & 1,7 \\
Consumo Domést. & 1,1 & 4,3 & 1,5 \\
Invest. Domést. & 4,8 & 13 & 2,5 \\
Juros Reais & 5,7 & 5,5 & 5,5 \\
Exportações Líq. & 47 & 250 & 130 \\
Câmbio Real & 11 & 1,2 & 1,3 \\
\hline
\end{tabular}

Vale notar que a correlação entre o PIB total, o PIB comercializável e o PIB doméstico é quase unitária. Esta foi a motivação para especificarmos nossas economias artificiais com um só choque tecnológico. O PIB comercializável é cerca de $50 \%$ mais volátil que o PIB total, e cerca de duas vezes mais volátil que o PIB doméstico, o que justifica a modelagem de desvios padrões distintos para cada setor. Dentro de cada setor, o investimento é aproximadamente três vezes mais volátil que o PIB, e o consumo é ligeiramente menos volátil. Vale notar também que consumos e investimento são fortemente pró-cíclicos, e que o setor doméstico parece mais correlacionado com o PIB do que o comercializável.

As exportações líquidas são contracíclicas e muito mais voláteis que as outras séries, um comportamento já observado em outros países. (CORREIA, NEVES \& REBELO, 1995). Contudo, devemos considerar o valor absoluto de sua volatilidade com certa desconfiança em virtude da necessidade da aproximação da função logarítmica à raiz. Os juros reais e o câmbio real também são contracíclicos, e bem mais voláteis que as outras séries.

Para melhor identificarmos a ligação entre os juros reais e a atividade econômica reproduzimos o exercício de Pastore e Pinotti (2000), obtendo a IS dinâmica. Como já mencionado, os parâmetros dessa estimação são robustos para diferentes amostras, e constituem um fato estilizado importante para verificarmos se a economia artificial reproduz os dados reais. 
Os fatos estilizados do Brasil parecem estar de acordo com a teoria neoclássica aplicada a uma economia aberta. Na presença de choques positivos de produtividade, o investimento cresce fortemente, aproveitando o aumento momentâneo da remuneração do capital; enquanto isso, o consumo sobe suavemente, devido à maior renda permanente. A possibilidade de comércio exterior faz com que o País financie parte do investimento externamente, e observa-se um déficit na balança comercial (importação de máquinas, novamente por causa do momento de alta produtividade). O consumo de comercializáveis sobe mais que o consumo de domésticos, em decorrência tanto da possibilidade de importar quanto da maior magnitude do choque nesse setor. Isto faz com que o câmbio real (que é o preço dos comercializáveis com relação aos domésticos) decresça.

Vale notar que por trás dessa lógica neoclássica a grandeza mais importante é a volatilidade do investimento proveniente do setor de comercializáveis. Isto porque é a magnitude desses investimentos que justifica o comportamento contracíclico das exportações líquidas e do câmbio real. Com isso em mente, nas economias simuladas escolhemos os parâmetros restantes $\left(\sigma_{T}, \sigma_{N}\right.$ e $\left.\phi\right)$ de modo a, primordialmente, obter a volatilidade da série de investimentos comercializáveis dos dados simulados próxima à dos dados reais. A seguir, na medida do possível, os parâmetros são escolhidos para aferir a volatilidade do produto dos comercializáveis e, posteriormente, do produto dos domésticos. Ao contrário do que possa inicialmente parecer, a presença de três variáveis de ajuste não permite o ajuste de três estatísticas.

A segunda coluna das Tabelas 1, 2 e 3 corresponde aos dados simulados em nossa economia artificial com agregação Leontieff. Os parâmetros correspondentes são $\sigma_{T}=2,0 \%, \sigma_{N}=1,5 \%$ e $\phi=30$, os quais fazem com que a volatilidade da série de investimento e produto comercializável das simulações seja igual à dos dados reais, mas são inúteis para ajustar as séries de domésticos. Uma conseqüência direta da forma de agregação Leontieff é fazer com que os investimentos provenientes de cada setor estejam fortemente relacionados. Isto tem como resultante que, para quaisquer parâmetros que experimentamos, o produto doméstico é mais volátil que o comercializável, mas não temos uma intuição cabal a respeito deste resultado. Não obstante, uma melhor intuição pode ser apreendida das Figuras 1 e 2 (vide apêndi- 
ce), que explicitam, respectivamente, as respostas a um impulso a choques tecnológicos e de juros de magnitudes iguais a um desvio padrão.

\section{TABELA 2 - CORRELAÇÕES (CONTEMPORÂNEAS) COM O PIB DAS} SÉRIES FILTRADAS

\begin{tabular}{lccc}
\hline Variável & Brasil & Leontieff & Cobb-Douglas \\
\hline PIB Comerc. & 0,94 & 0,95 & 0,98 \\
Consumo Comerc. & 0,57 & 0,99 & 0,99 \\
Invest. Comerc. & 0,55 & 0,95 & 0,66 \\
PIB Domést. & 0,97 & 0,99 & 0,95 \\
Consumo Domést. & 0,86 & 0,99 & 0,99 \\
Invest. Domést. & 0,82 & 0,95 & 0,69 \\
Juros Reais & $-0,11$ & $-0,10$ & $-0,23$ \\
Exportações Líq. & $-0,40$ & $-0,93$ & $-0,23$ \\
Câmbio Real & $-0,38$ & 0,44 & $-0,95$ \\
\hline
\end{tabular}

TABELA 3 - CURVA IS DINÂMICA. (VARIÁVEL DEPENDENTE: HIATO DO PRODUTO)

\begin{tabular}{lccc}
\hline Variável & Brasil & Leontieff & Cobb-Douglas \\
\hline Constante & 0,0077 & 0,0043 & 0,0043 \\
hiato $(-1)$ & $(0,0042)$ & 0,64 & 0,62 \\
Juros Reais & $(0,49$ & $-0,14)$ & $-0,081$ \\
& $-0,12$ & $-0,082$ & \\
\hline
\end{tabular}

Desvios padrões entre parênteses.

Os itens de (a) a (d) de cada figura correspondem ao caso de agregação Leontieff. Note que um choque tecnológico leva a aumentos das horas trabalhadas e investimento doméstico, mas, contra-intuitivamente, implica redução do investimento comercializável. A provável razão para esse fenômeno decorre da expressiva redução de consumo. Em outras palavras, caso o investimento em comercializáveis também aumentasse, o consumo seria excessivamente reprimido, devido ao já presente efeito da elevação do investimento doméstico.

Vale ressaltar, contudo, que a correlação do investimento comercializável é positiva com o produto, em linha com os dados reais. Isto ocorre porque os choques de juros implicam reduções tanto das horas trabalhadas como 
do investimento (Figura 2), gerando uma relação positiva entre esse investimento e o produto.

Por outro lado, o comportamento do investimento comercializável (quando de choques tecnológicos) causa uma relativa redução do produto de comercializáveis, quando comparado ao produto de domésticos. Este fenômeno, por sua vez, é o provável responsável pelo comportamento pró-cíclico do câmbio real, que contraria o dos dados reais.

A última coluna das Tabelas 1,2 e 3 mostra a performance da nossa economia artificial com agregação Cobb-Douglas. Os parâmetros correspondentes são $\sigma_{T}=1,4 \%, \sigma_{N}=0,45 \%$ e $\phi=350$. Note que as volatilidades dos dados simulados estão bem mais próximas às dos dados reais do que na economia anterior, e que as correlações com o PIB têm sempre o sinal correto. Os principais desvios, discutidos adiante, parecem ser nas volatilidades das exportações líquidas, do câmbio real, e do investimento de domésticos.

Os itens (e) a (h) das Figuras l e 2 mostram as respostas-impulso dessa economia. Ao contrário da economia com agregação Leontieff, a economia com agregação Cobb-Douglas apresenta respostas-impulso bastante intuitivas. Talvez a única surpresa seja o efeito particularmente reduzido de choques nos juros sobre os investimentos.

Conforme já mencionado, a volatilidade das exportações líquidas deve ser considerada com desconfiança em virtude da aproximação realizada da função logarítmica em torno de um ponto extremamente sensível. A título de comparação, obtivemos a volatilidade dessa série no período de 1980a 2001, e um desvio padrão igual a 130, equivalente ao valor aqui obtido.

O câmbio real resultante das simulações efetuadas é quase dez vezes menos volátil que o câmbio real observado nos dados reais, um sinal de grande discrepância. Uma primeira explicação para esse resultado reside na hipótese de completa flexibilidade de preços de nossa economia. Conforme extensamente discutido na literatura (vide OBSTFELD \& ROGOFF, 1995), parece haver um forte suporte empírico para a hipótese de rigidez nos preços, que explica desvios permanentes do câmbio real de seu valor de equilíbrio. Esta 
explicação sugere a construção de modelos com preços fixos, como pesquisa futura. Uma segunda razão, passível de investigação em nosso arcabouço, é que a elasticidade de substituição entre o consumo de comercializáveis e domésticos seja inferior à obtida por Ostry e Reinhart (1992). De fato, a profissão parece desconfiar da robustez desse estudo, mas a literatura não oferece outros. Para verificar a robustez desse parâmetro, experimentamos valores menores para $\rho$ em nossa economia Cobb-Douglas. Em especial, quando $\rho=-10$, todas as correlaçóes e volatilidades dos valores simulados não se alteram, à exceção da volatilidade do câmbio real. Esta passa a ser $11 \%$, igualando-se à observada nos dados brasileiros. Isto não significa dizer que rigidez de preços não seja um importante efeito a ser considerado, mas que talvez seu efeito seja menor do que o que imaginamos.

A última discrepância refere-se à volatilidade dos investimentos provenientes do setor doméstico. Note-se que os dados simulados têm cerca de metade da volatilidade dos dados reais, apesar de o produto apresentar volatilidades semelhantes. Uma possível explicação, baseada no problema de aproximação computacional acima citado, é que nossa economia artificial não captura a queda dos retornos dos investimentos de comercializáveis na formação de capital, fazendo com que menos investimento de domésticos sejam necessários.

\section{CONCLUSÕES}

Construímos um modelo de equilíbrio geral dinâmico de dois setores que é calibrado de acordo com a economia brasileira. Quando os investimentos dos dois setores (comercializáveis e domésticos) são agregados de acordo com uma Cobb-Douglas nas leis de formação de capital, o modelo implica simulações bastante consistentes com as freqüências altas das séries macroeconômicas brasileiras. Em especial, o modelo reproduz as volatilidades cíclicas dos componentes das contas nacionais e a natureza contracíclica das exportações líquidas e do câmbio real. Nesse sentido, o presente trabalho sugere o sucesso da aplicação da modelagem de ciclos reais para o Brasil, mesmo quando as séries estão desagregadas em dois setores. 
Por outro lado, a comparação das séries simuladas com os dados originais também aponta para algumas discrepâncias, as quais sugerem novos caminhos para pesquisa futura. Um deles é a modelagem explícita de preços rígidos, a qual provavelmente implicaria volatilidades do câmbio real mais em linha com as observadas. Outro possível caminho é a mudança na forma de aproximação para a solução da equação de Bellman, a qual se torna importante caso queiramos aprender mais sobre a forma de agregação dos investimentos. No momento atual é praticamente impossível recorrer a métodos computacionais que não apelem para aproximações do tipo linear-quadrática sem incorrer em problemas de "excesso de dimensões". Mas é provável que com o rápido avanço computacional possamos, num futuro próximo, utilizar aproximações de estados discretos (JUDD, 1998), robustas para qualquer forma de agregação.

\section{REFERENCIAS}

CHRISTIANO, L. J.; EICHENBAUM, M.; EVANS, C. L. Sticky price and limited participation models of money: a comparison. European Economic Review 41, p. 1201-1249, 1997.

COOLEY, T. F. Frontiers of business cycle research. Princeton University Press, 1995.

CORREIA, I.; NEVES, J.; REBELO, S. Business cycles in a small open economy. European Economic Review 39, p. 1089-1113, 1995.

GREENWOOD, J.;HERCOWITZ, Z.; HUFFMAN, G. Investment, capacity utilization and the business cycle. American Economic Review 78 , p. 402-417, 1988.

JUDD, K. L. Numerical methods in economics. The MIT Press, 1998.

KANCZUK, F. Business cycles in a small open Brazilian economy. Economia Aplicada, v. 5, n. 3, p. 455-471, jul./set. 2001.

. Juros reais e ciclos reais brasileiros. Revista Brasileira de Economia, v. 56, n. $2,2002$.

KANCZUK, F.; FARIA JR, F. Ciclos reais para a indústria brasileira. Estudos Econômicos, v. 30, n. 3, p. 335-350, jul./set. 2000.

OBSFELD, M.; ROGOFF, K. Foundations of international macroeconomics. MIT Press, 1995.

OSTRY, J. D.; REINHART, C. M. Private savings and terms of trade shocks. IMF Staff Papers 39, p. 495-517, 1992. 
PASTORE, A. C.; PINOTTI, M. C. One year of inflation targeting in Brazil: what have we learned about the channels of monetary transmission. 2000. Mimeografado.

PESSÔA, S. A. Ajustamento de uma economia após elevação da produtividade. Pesquisa e Planejamento Econômico, v. 29, n. 1, p. 323-371, 1999.

STOCKMAN, A. C.; TESAR, L. Tastes and technology in a two-country model of the business cycle: explaining international comovements. American Economic Review, 85, p. 168-85, 1995.

TAYLOR, J. B. Monetary policy rules. The University of Chicago Press, 1999.

\section{APENNDICE}

FIGURA 1 - RESPOSTAS IMPULSO A CHOQUES TECNOLÓGICOS

\section{FIGURA IA: LEONTIEFF, Ht}

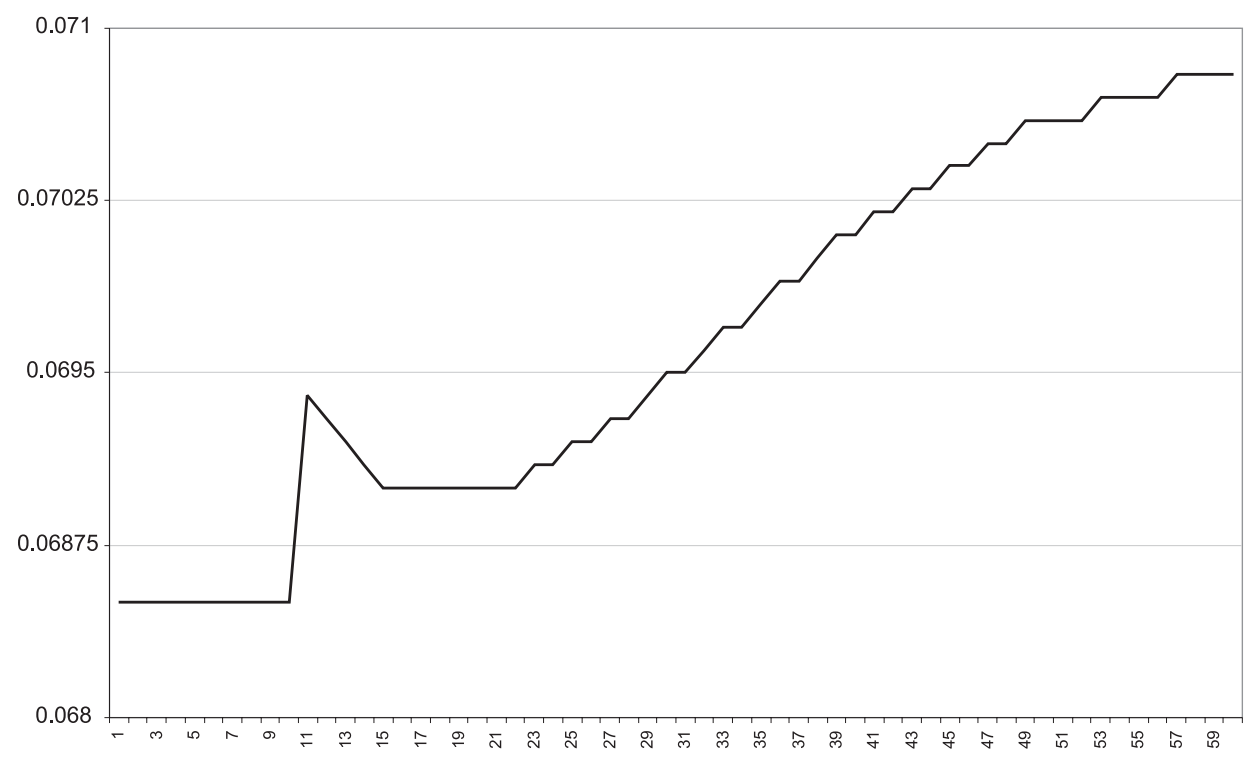




\section{FIGURA IB: LEONTIEFF, Hn}

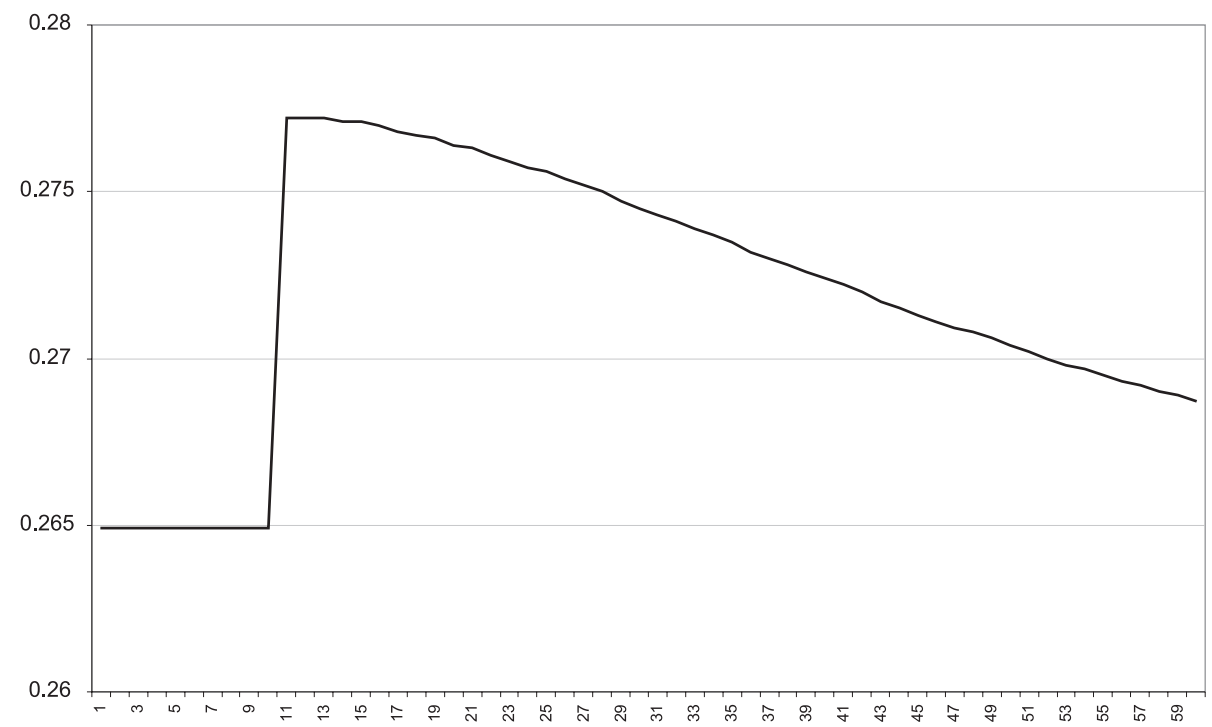

FIGURA IC: LEONTIEFF, It

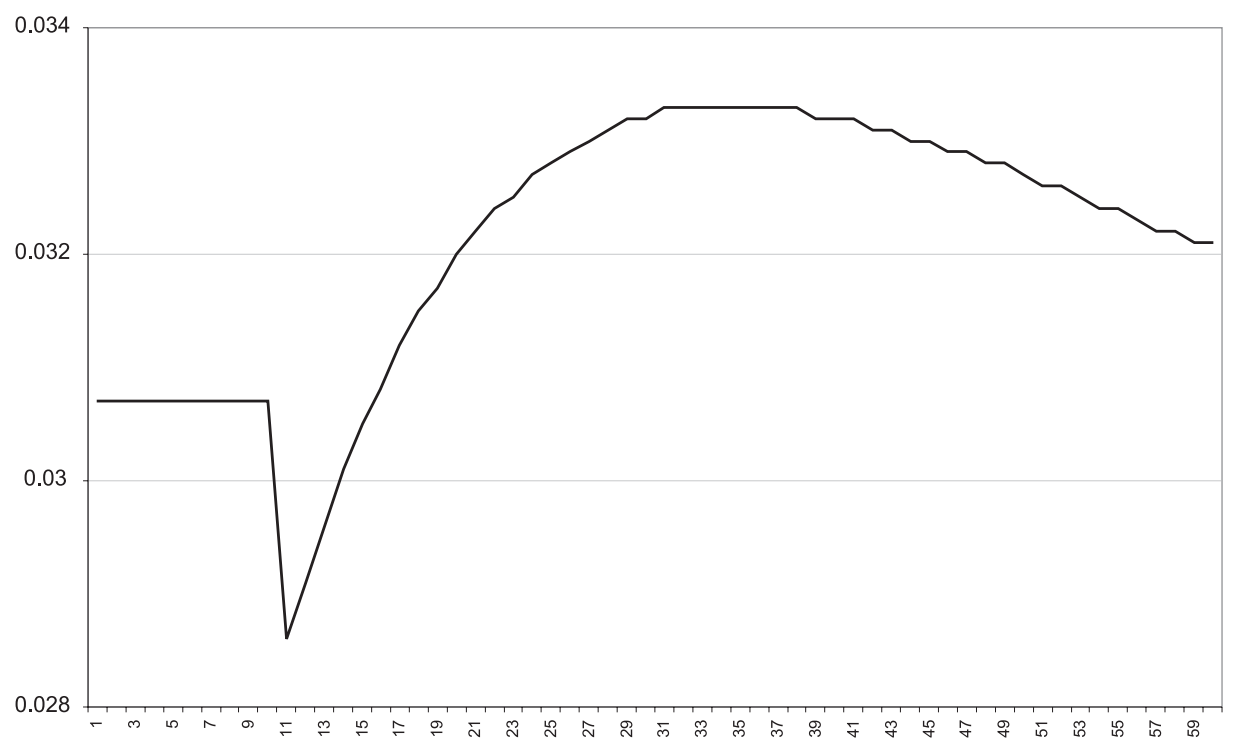


FIGURA ID: LEONTIEFF, In

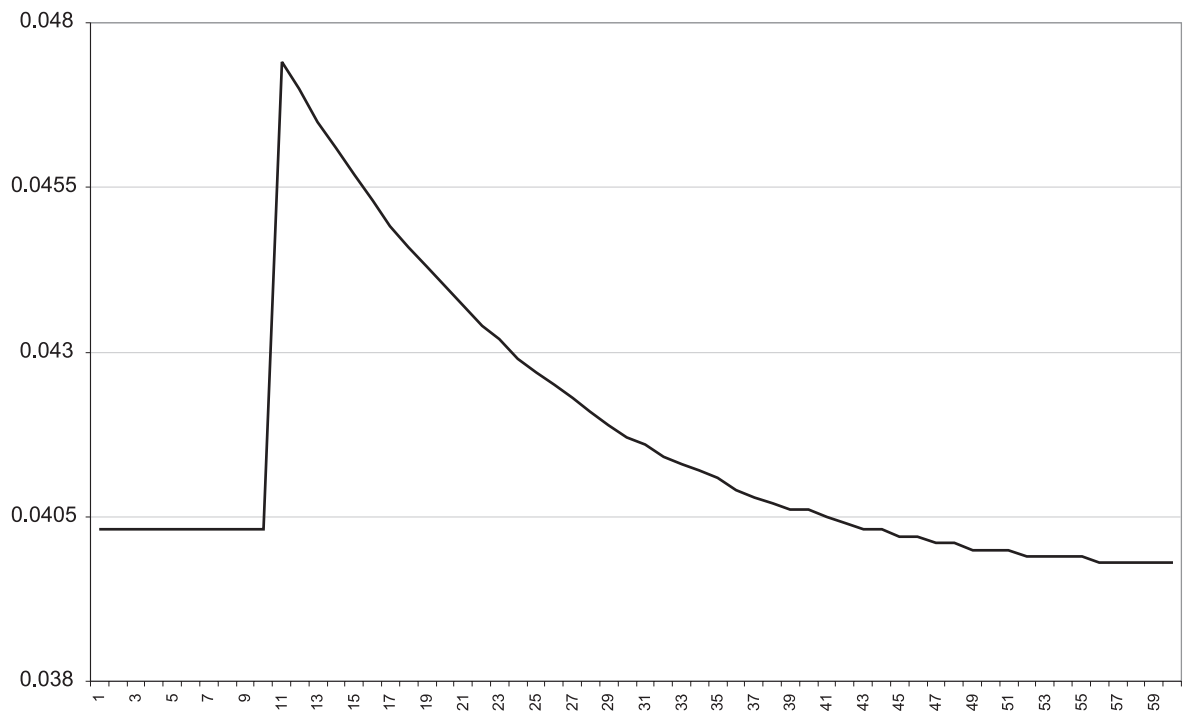

FIGURA IE: COBB-DOUGLAS, Ht

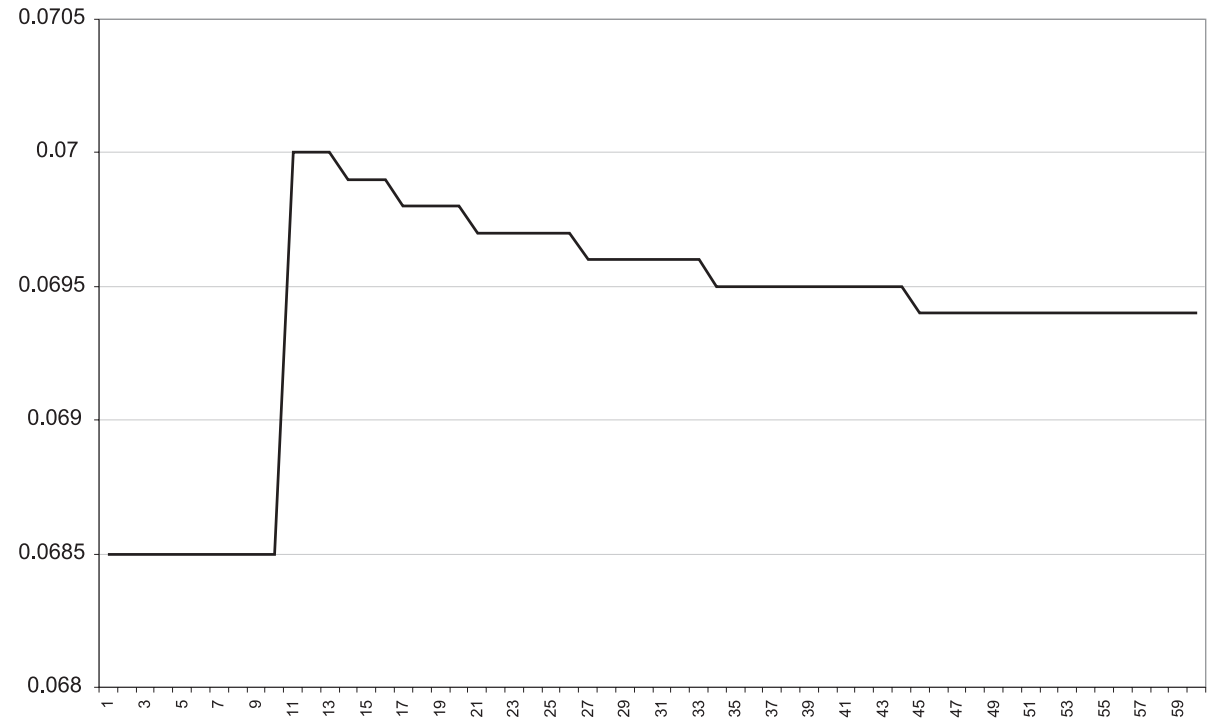


FIGURA IF: COBB-DOUGLAS, Hn

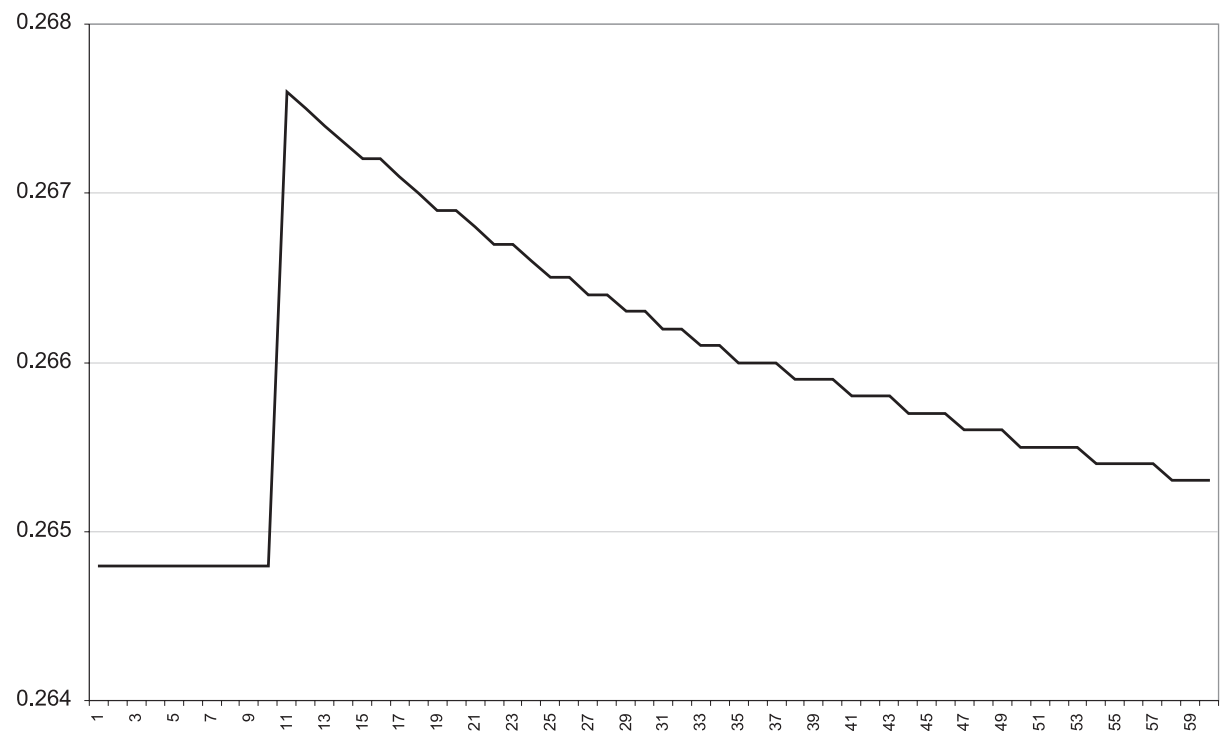

FIGURA IG: COBB-DOUGLAS, It

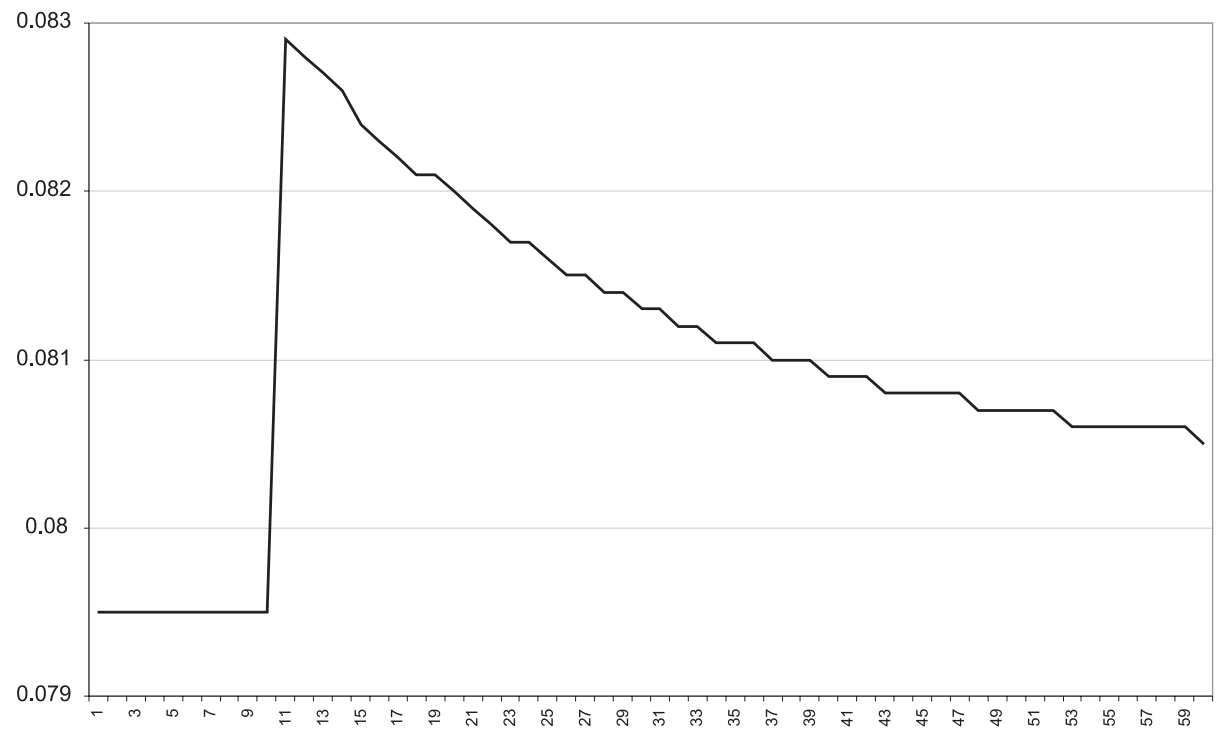


FIGURA IH: COBB-DOUGLAS, In

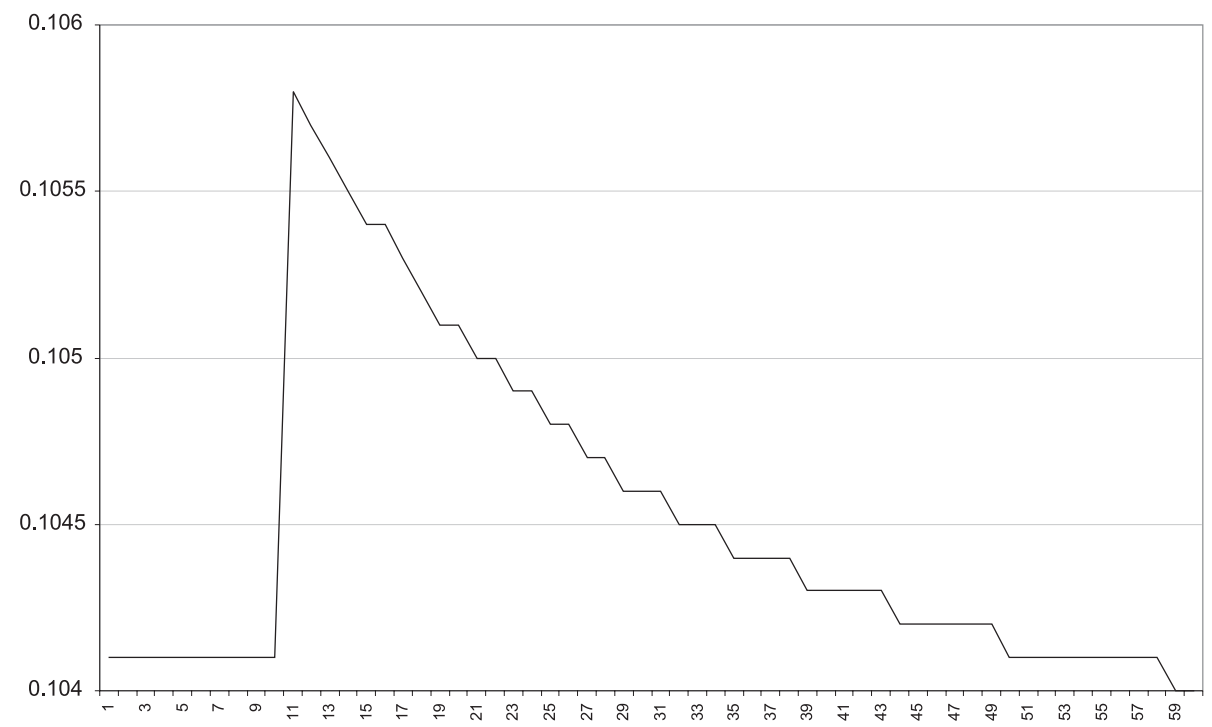

FIGURA 2 - RESPOSTAS IMPULSO A CHOQUES NOS JUROS

FIGURA 2A: LEONTIEFF, $\mathrm{Ht}$

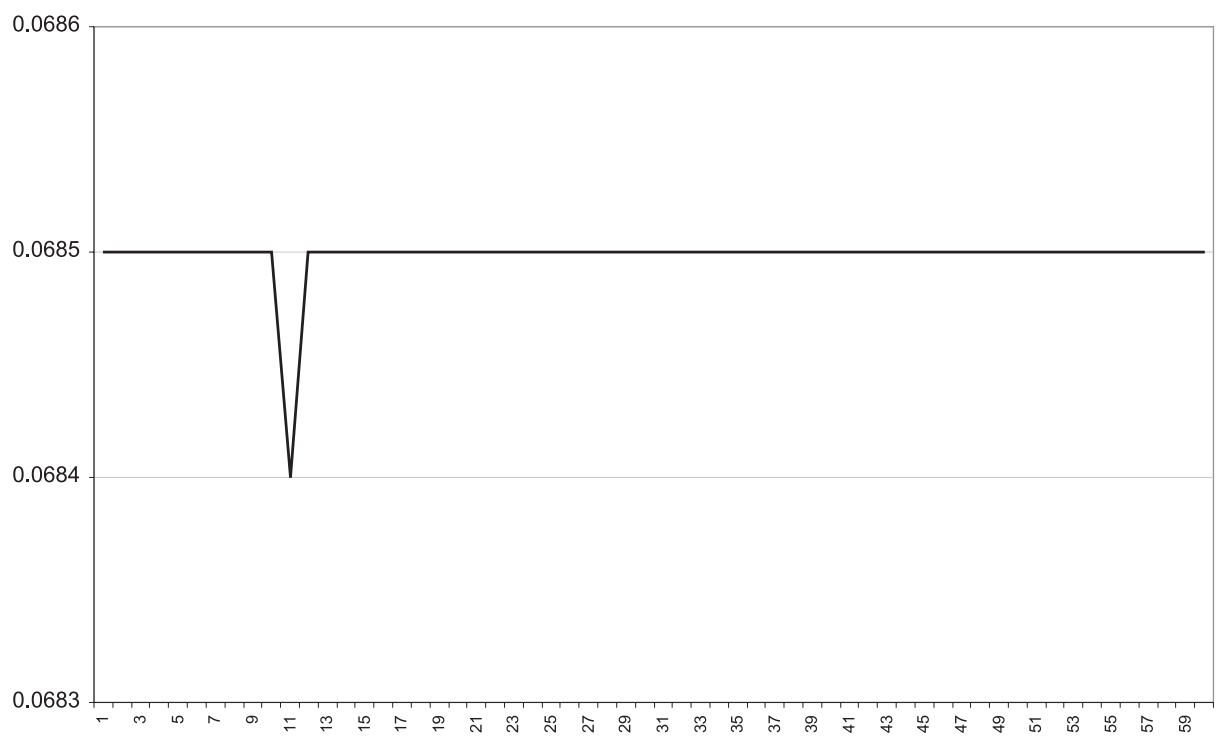


FIGURA 2B: LONTIEFF, $\mathrm{Hn}$

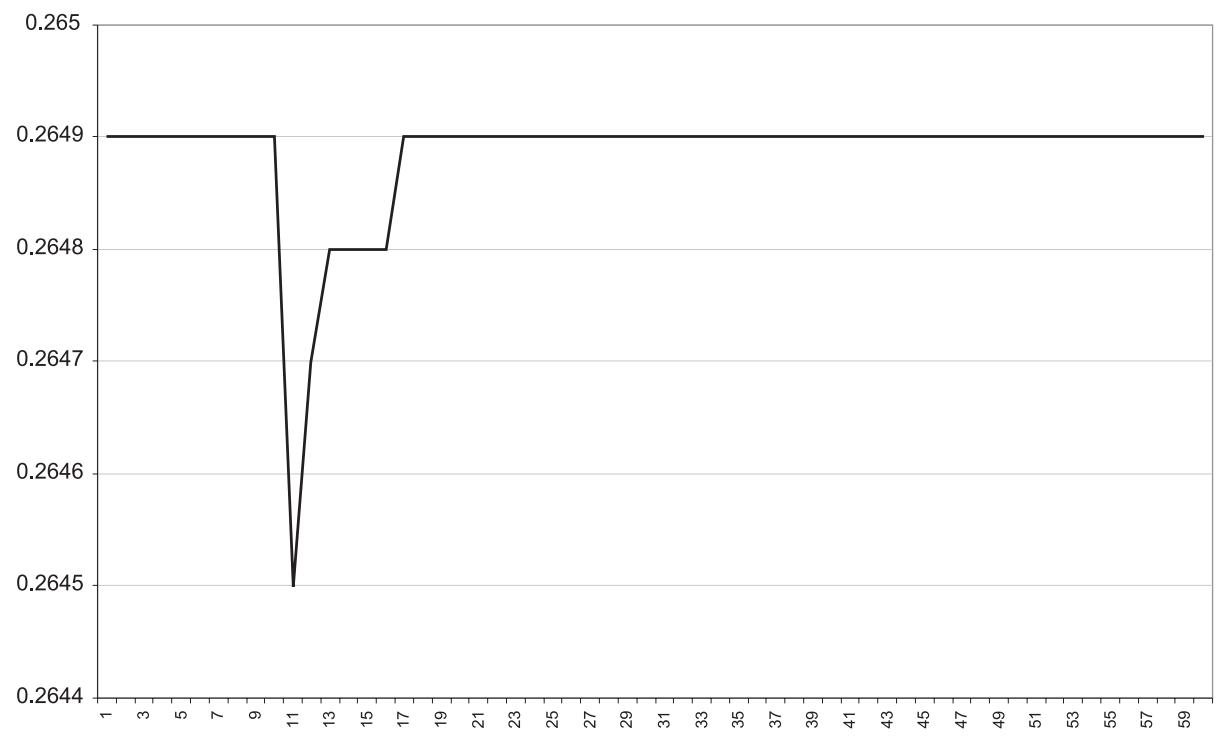

FIGURA 2C: LEONTIEFF, It

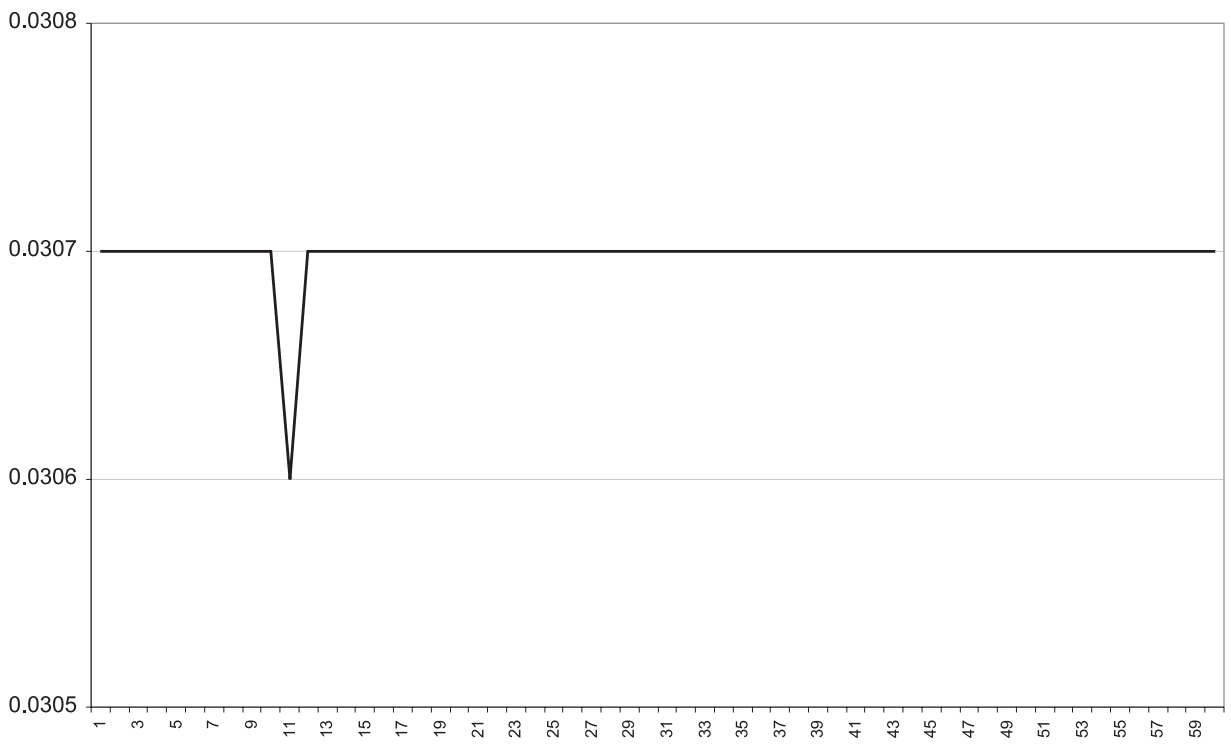


FIGURA 2D: LEONTIEFF, In

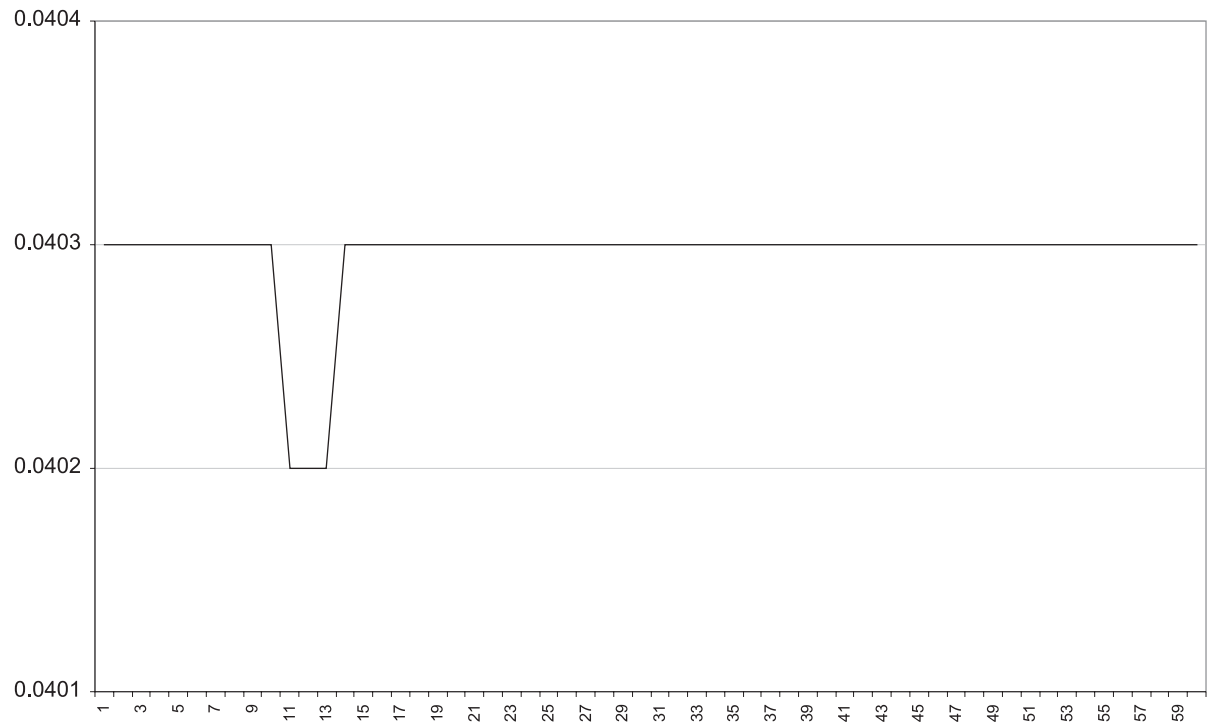

FIGURA 2E: COBB-DOUGLAS, $\mathrm{Ht}$

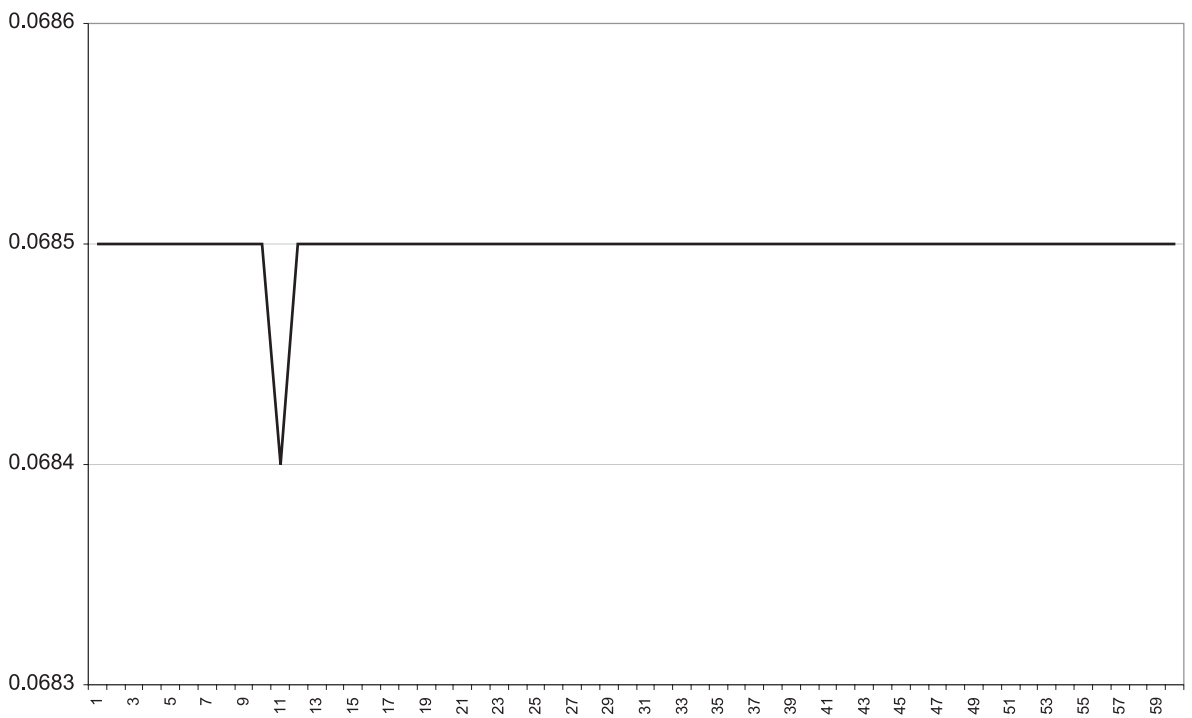


FIGURA 2F: COBB-DOUGLAS, Hn

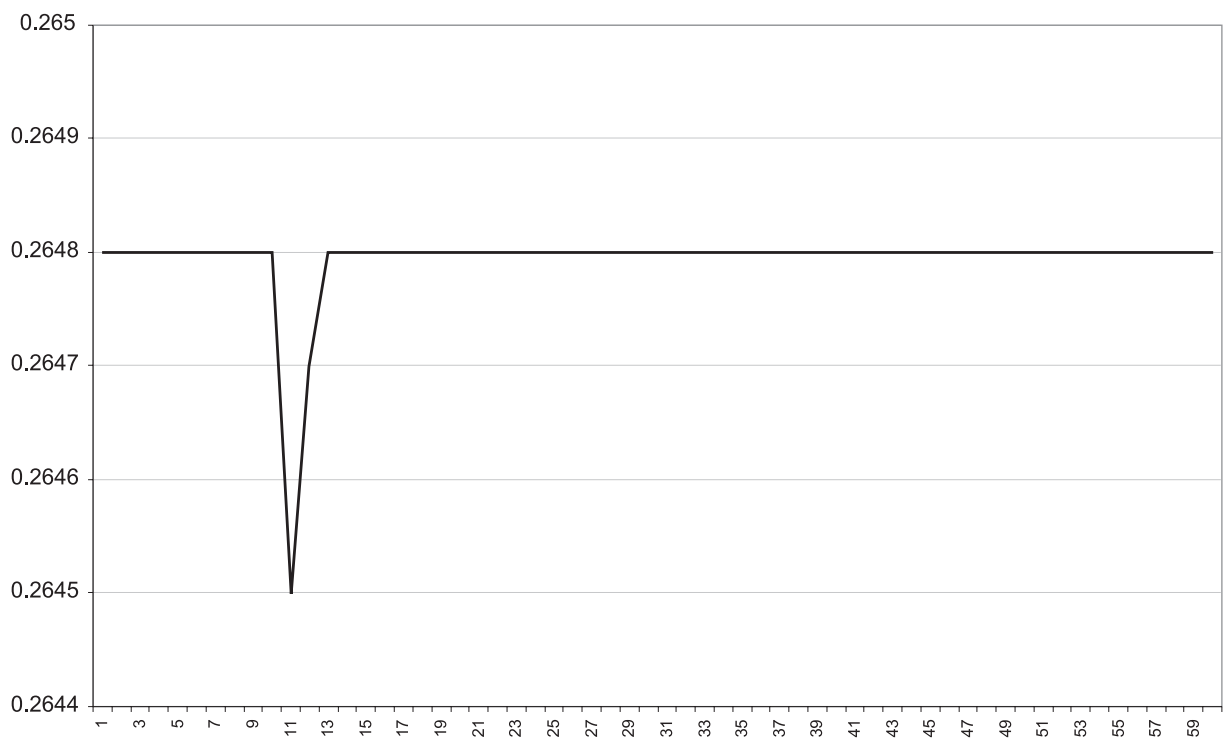

FIGURA 2G: COBB-DOUGLAS, It

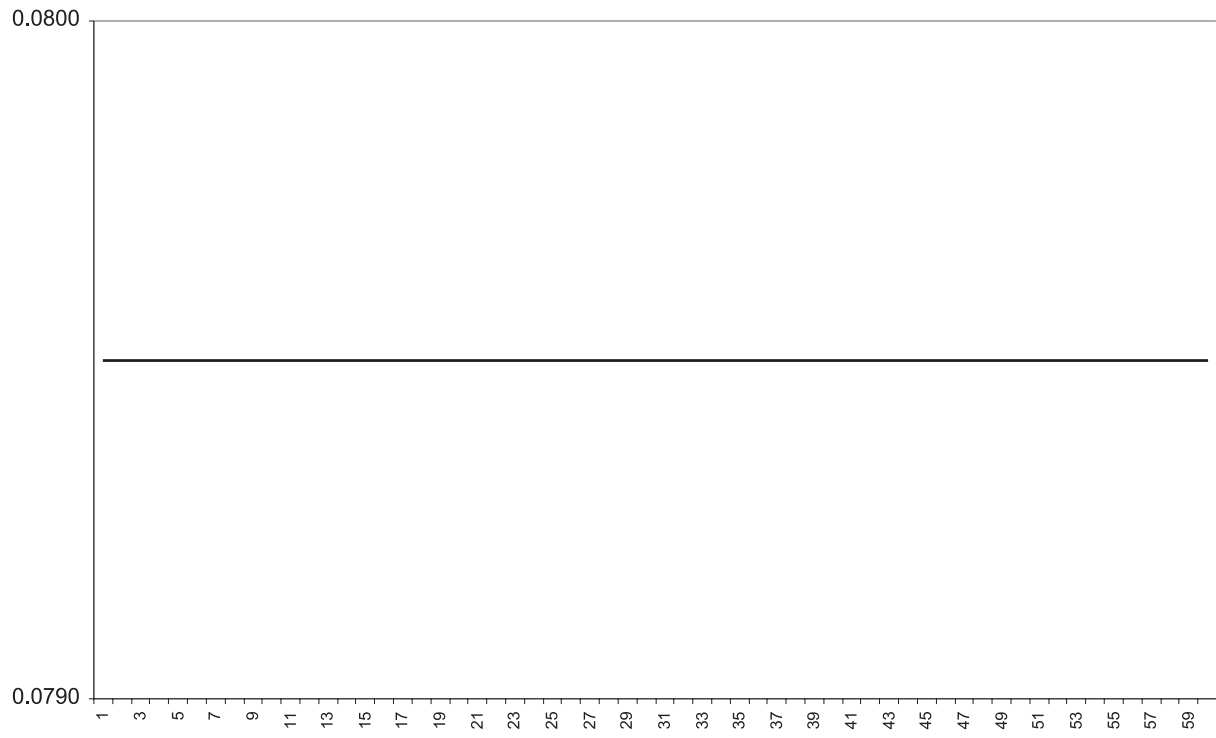


FIGURA 2H: COBB-DOUGLAS, In

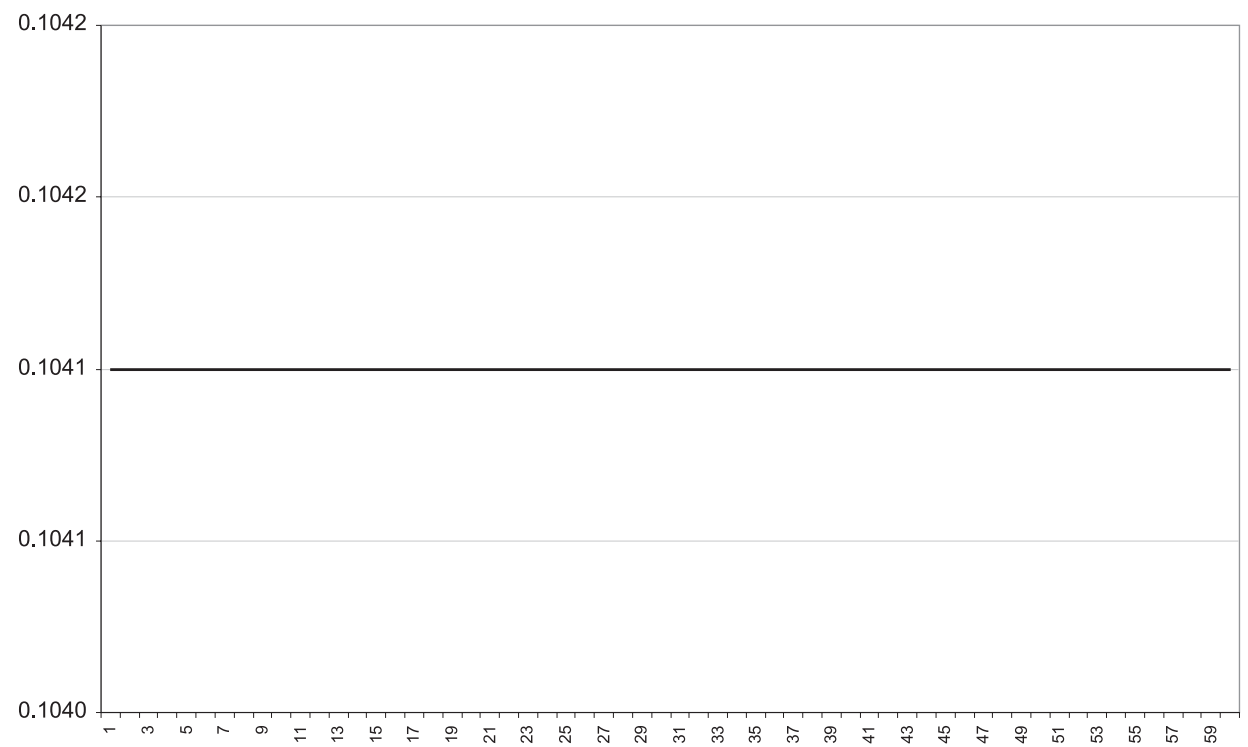

(Recebido em fevereiro de 2002. Aceito para publicação em agosto de 2003). 